\title{
Long noncoding AFAP1-antisense RNA 1 is upregulated and promotes tumorigenesis in gastric cancer
}

\author{
FEI YE, YI GONG, XIANGHENG CHEN, MEIYING YU, ZHONGKUN ZUO, \\ DONGNI PEI, WEI LIU, QUNWEI WANG, JUN ZHOU, LUNXI DUAN, LEIYI ZHANG, \\ XIAOJING LI, TENGLONG TANG and JIANGSHENG HUANG \\ Department of Minimally Invasive Surgery, The Second Xiangya Hospital of \\ Central South University, Changsha, Hunan 410011, P.R. China
}

Received August 31, 2016; Accepted April 28, 2017

DOI: $10.3892 / \mathrm{ol} .2018 .8266$

\begin{abstract}
Long noncoding RNA serves important roles in gastric cancer (GC). However, the prognostic significance and tumorigenesis effect of AFAP1-antisense RNA 1 (AS1) in GC remain to be clarified. The present study was conducted in order to determine the expression level of AFAP1-AS1 by reverse transcription-quantitative polymerase chain reaction. It was demonstrated that AFAP1-AS1 expression level was higher in GC tissues in comparison with adjacent tissues. By analyzing 66 GC tissue specimens, AFAP1-AS1 expression level was found to be markedly associated with tumor size, clinical stage and differentiation. By performing multivariate Cox regression test, AFAP1-AS1 expression level was confirmed to be an independent factor for poor prognosis in patients with GC. Furthermore, SGC-7901 and BGC-823 cells were used for further investigation following transfection of an AFAP1-AS1 short hairpin RNA lentiviral vector. Knockdown of AFAP1-AS1 significantly inhibited GC cell proliferation, migration and invasion abilities in vitro. Finally, nude mice experiments confirmed that downregulation of AFAP1-AS1 in GC cells suppressed tumor growth in vivo. In conclusion, the results of the present study suggested that AFAP1-AS1 may serve as a valuable prognostic indicator and therapeutic target for GC.
\end{abstract}

\section{Introduction}

Gastric cancer (GC) is a major type of digestive tract tumor (1). According to statistical studies 951,000 novel cases are diagnosed, and $\sim 723,000$ mortalities occur each

Correspondence to: Professor Jiangsheng Huang, Department of Minimally Invasive Surgery, The Second Xiangya Hospital of Central South University, 139 Renmin Road, Changsha, Hunan 410011, P.R. China

E-mail: hjs13907313501@yahoo.com

Key words: AFAP1-antisense RNA 1, long noncoding RNA, gastric cancer, prognosis, proliferation year worldwide $(2,3)$. There has been a significant rise of GC cases and GC associated mortalities over the past decades, accounting for $\sim 8.8 \%$ of the mortality rate worldwide (4). Surgical resection is one of the most important methods for early gastric cancer treatment (5). At present, due to diagnostic and therapeutic advancements, the survival rate of patients with GC has increased (6). However, poor prognosis is still observed in patients with GC (7). The overall five-year survival rate of patients with GC remains low (8). Further study investigating the molecular mechanisms underlying GC tumorigenesis may provide promising therapeutic targets for GC.

Recent studies have revealed a large-scale regulatory network generated by non-coding RNAs, including long noncoding RNAs (lncRNAs) and microRNAs (miRNAs) $(9,10)$. lncRNAs are conserved non-coding RNAs of $>200$ nucleotides (11). An increasing amount of evidence has indicated that dysregulation of lncRNAs is involved in numerous types of cancer, including GC (12). A series of lncRNAs involved in $\mathrm{GC}$ tumor development has been revealed by previous studies (13). It has been demonstrated that the expression level of lncRNA AFAP1-antisense RNA 1 (AS1) was significantly upregulated ( 45 -fold) in 3 gastric cancer tissues compared with in normal tissues by lncRNA microarray analysis (14), which indicated that AFAP1-AS1 may function as a tumor promoter in GC. To the best of our knowledge, the associations between AFAP1-AS1 expression level and clinicopathological parameters in patients with GC, and the potential mechanisms underlying the role of AFAP1-AS1 in GC tumorigenesis, have not yet been studied. The present study aimed to detect the expression level of AFAP1-AS1 in GC tissues and cells and confirm whether AFAP1-AS1 serves an important role in GC development.

\section{Materials and methods}

Tissue samples and cell lines. The present study was approved by the Ethics Committee of The Second Xiangya Hospital of Central South University (Changsha, China), and written informed consent was obtained from all patients prior to enrollment in the present study. Criteria for accepting patients were as follows: i) Patients were treated with gastrectomy at 
The Second Xiangya Hospital of Central South University; ii) pathological confirmation of GC following surgery; iii) no preoperative anticancer treatment was received by patients with GC; iv) patients exhibited no other cancer history; and v) the adjacent normal tissues were located $>2 \mathrm{~cm}$ away from the tumor. A total of 10 pairs of human GC tissues and corresponding matched normal tissues, and 56 samples of unmatched GC tissues were selected according to the inclusion criteria. A total of 66 patients with GC who underwent gastrectomy from January 2014 to May 2016 were prospectively enrolled. The median follow-up period of patients with GC was 13 months.

GES-1 human gastric epithelial cells and HGC-27, MGC-803, BGC-823 gastric cancer cell lines were obtained from the American Type Culture Collection (Manassas, VA, USA). SGC-7901 cell lines were purchased from the Type Culture Collection of the Chinese Academy of Sciences (Shanghai, China). MGC-803, BGC-823 and SGC-7901 cells were cultured in high-glucose Dulbecco's modified Eagle's medium (DMEM; Gibco; Thermo Fisher Scientific, Inc., Waltham, MA, USA) and GES-1 and HGC-27 cells were cultured in RPMI-1640 medium (Gibco; Thermo Fisher Scientific, Inc.). All media were supplemented with $10 \%$ fetal bovine serum (FBS; Invitrogen; Thermo Fisher Scientific, Inc.) and $1 \%$ penicillin-streptomycin mixture (Invitrogen; Thermo Fisher Scientific, Inc.) at $37^{\circ} \mathrm{C}$ in a humidified environment containing $5 \% \mathrm{CO}_{2}$.

Transfection and reverse transcription-quantitative polymerase chain reaction ( $R T-q P C R$ ). pGreenPuro ${ }^{\mathrm{TM}}$ (human cytomegalovirus) short hairpin (sh)RNA vectors were inserted into two shRNA-AFAP1-AS1 or scrambled control shRNA (shNC) vectors (sh1AFAP1-AS1 and sh2AFAP1-AS1), respectively. The sequences were as follows: sh1AFAP1-AS1 forward, 5'-CCG GAGCGGTCTCAGCCGAATGACTCTCGAGAGTCATT CGGCTGAGACCGCTTTTTTG-3' and reverse, 5'-AATTCA AAAAAGCGGTCTCAGCCGAATGACTCTCGAGAGTCA TTCGGCTGAGACCGCT-3'; sh1AFAP1-AS2 forward, 5'-CCG GAACACCAATCCCAAGAGGTGACTCGAGTCACCTCT TGGGATTGGTGTTTTTTTG-3' and reverse, 5'-AATTCA AAAAAACACCAATCCCAAGAGGTGACTCGAGTCACC TCTTGGGATTGGTGTT-3'. The shNC sequences were as follows: Forward, 5'-CCGGTTTCTCCGAACGTGTCACGT CTCGAGACGTGACACGTTCGGAGAATTTTTG-3' and reverse, 5'-AATTCAAAAAGTTCTCCGAACGTGTCACGT CTCGAGACGTGACACGTTCGGAGAA-3'); and used as negative control. These aforementioned recombinant lentiviruses vectors were purchased from Huayueyang Biotechnology, Co., Ltd. (Beijing, China). BGC-823 and SGC-7901 cells were transfected (Lipofectamine ${ }^{\mathrm{TM}}$ 3000; Thermo Fisher Scientific, Inc.) with sh1AFAP1-AS1, sh2AFAP1-AS1 or shNC according to the manufacturer's protocol. In brief, when cell cultures reached $90 \%$ confluence in 6-well plates, the recombinant lentiviruses were diluted in $2 \mathrm{ml}$ DMEM containing 10\% FBS in the presence of polybrene $(8 \mu \mathrm{g} / \mathrm{ml}$, Sigma-Aldrich; Merck $\mathrm{KGaA}$, Darmstadt, Germany) and were incubated with the cells for $6 \mathrm{~h}$. Next, the cells were incubated with $2 \mathrm{ml}$ fresh $10 \%$ FBS Polybrene-DMEM for $48 \mathrm{~h}$. Total RNA from tissue specimens and cells was extracted using TRIzol ${ }^{\circledR}$ reagent (Invitrogen; Thermo Fisher Scientific, Inc.), according to the manufacturer's protocol. RNA amplification was performed as previously described (15). GAPDH was used to normalize mRNA expression levels. The $2^{-\Delta \Delta \mathrm{Cq}}$ method was performed as previously described (16). Sequences of the insertion vectors and primers are presented in Table I.

Cell proliferation assay. Cell Counting kit-8 (CCK-8) assay (Dojindo Molecular Technologies, Inc., Kumamoto, Japan) was used to determine cell viability. BGC-823 and SGC-7901 cells were plated in a $96-$-well plate with a density of $5 \times 10^{3}$ cells/well. Following transfection and culturing for $12 \mathrm{~h}, \mathrm{CCK}-8$ reagents were added to each well at various time points $(0,24,48$ and $72 \mathrm{~h}$ ), and further incubated at $37^{\circ} \mathrm{C}$ for $2 \mathrm{~h}$. The viable cells were evaluated by detection of absorbance $(450 \mathrm{~nm})$ using a Multiskan $^{\mathrm{TM}}$ spectrophotometer (Thermo Fisher Scientific, Inc.).

Scratch migration assays. At $24 \mathrm{~h}$ after transfection with sh1AFAP1-AS1 or shNC, BGC-823 and SGC-7901 cells were seeded in $24-w e l l$ plates $\left(1 \times 10^{5}\right.$ cells/well), respectively. Once cells reach $90 \%$ confluence, a $200 \mu \mathrm{l}$ tip was used to produce a wound line on the cell monolayer. Images were captured at 0 and $48 \mathrm{~h}$ by inverted light microscopy to determine the rate of gap closure. The distance between two edges was evaluated by ImageJ v1.8.0 software (National Institutes of Health, Bethesda, MD, USA).

Matrigel invasion assay. The invasion ability of GC cells was determined by Matrigel assay. Cells were plated in 24 -well plates $\left(1 \times 10^{5}\right.$ cells/well) on the top chamber with $8 \mu \mathrm{m}$ pore size and Matrigel-coated chambers. Serum-free DMEM was added to the top chamber. The bottom chamber contained $700 \mu \mathrm{l}$ DMEM with $20 \%$ FBS. After $24 \mathrm{~h}$, cells on the upper surface were removed, while cells attached to the bottom membranes were fixed in $4 \%$ paraformaldehyde (30 min at room temperature) and stained with $0.1 \%$ crystal violet (10 $\mathrm{min}$ at room temperature). Images of the Matrigel assays were captured by light microscopy and the number of invasive cells was evaluated by determining the absorbance at $570 \mathrm{~nm}$.

Tumorigenicity assays in nude mice. The animal experiments were approved by the Ethics Committee of The Second Xiangya Hospital of Central South University. All experiments were performed according to the National Institutes of Health animal care guidelines. Male BALB/c nude mice (4-6 weeks old; $15-20 \mathrm{~g}$ ) were purchased from the Animal Laboratory of Central South University (Changsha, China) and randomly separated into the blank control group or the shAFAP1-AS1 group (3 mice per group). All mice were maintained under specific pathogen-free conditions $\left(28^{\circ} \mathrm{C}, 10 \mathrm{~h} \mathrm{light}\right.$ and $14 \mathrm{~h}$ darkness) and ad libitum intake of water and food. BGC-823 or SGC-7901 cells ( $2 \times 10^{6}$ cells/mouse) were stably transfected with sh1AFAP1-AS1 or shNC vectors were injected subcutaneously into the right axilla $(200 \mu \mathrm{l})$. All nude mice were sacrificed 42 days following tumor implantation, xenografts were dissected and tumor volume and weight were assessed. Tumor volume was determined using the following formula: Volume $=0.5 \times \mathrm{a} \mathrm{x} \mathrm{b}^{2}$, where $\mathrm{a}$ is the longest diameter and $\mathrm{b}$ is the transverse diameter. 
Table I. Sequences of the insertions in vectors and primers.

\begin{tabular}{ll}
\hline Name & \multicolumn{2}{c}{ Sequence } \\
\hline $\begin{array}{l}\text { Insertion vector } \\
\text { sh1AFAP1-AS1 }\end{array}$ & F: 5'-CCGGAACACCAATCCCAAGAGGTGACTCGAGTCACCTCTTGGGATTGGTGTTTTTTG-3' \\
R:5'-AATTCAAAAAAACACCAATCCCAAGAGGTGACTCGAGTCACCTCTTGGGATTGGTGTT-3' \\
sh2AFAP1-AS1 & F: 5'-CCGGAGCGGTCTCAGCCGAATGACTCTCGAGAGTCATTCGGCTGAGACCGCTTTTTTG-3' \\
& R:5'-AATTCAAAAAAGCGGTCTCAGCCGAATGACTCTCGAGAGTCATTCGGCTGAGACCGCT-3' \\
shNC & F: 5'-CCGGTTTCTCCGAACGTGTCACGTCTCGAGACGTGACACGTTCGGAGAATTTTG-3' \\
& R: 5'-AATTCAAAAAGTTCTCCGAACGTGTCACGTCTCGAGACGTGACACGTTCGGAGAA-3' \\
Primer & \\
AFAP1-AS1 & F: 5'-TCGCTCAATGGAGTGACGGCA-3' \\
& R: 5'-CGGCTGAGACCGCTGAGAACTT-3' \\
GAPDH & F: 5'-TTAGTCGTCAATGGCAACAAG-3' \\
& R: 5'-GACACCGACGACGAACATAG-3'
\end{tabular}

sh, short hairpin; AFAP1-AS1, AFAP1-antisense RNA 1; shNC, scrambled control shRNA; F, forward; R, reverse.
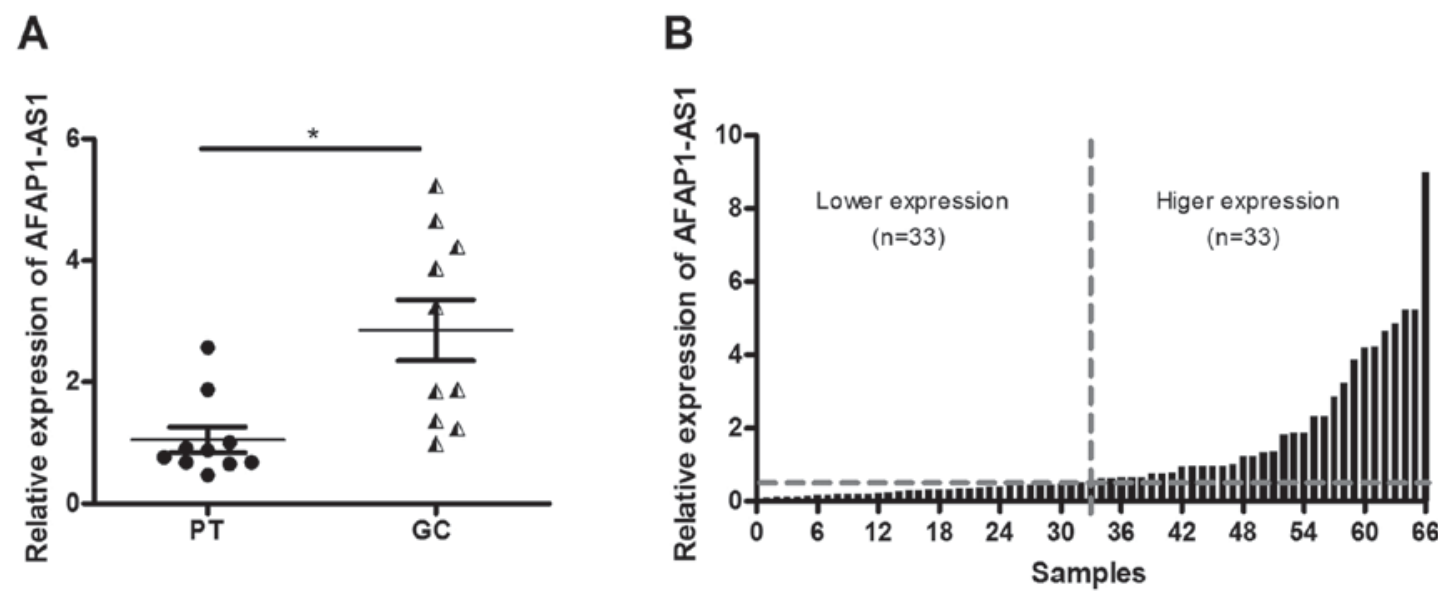

Figure 1. Expression levels of AFAP1-AS1 and clinicopathological characteristics in GC. (A) Comparison of AFAP1-AS1 expression levels in GC tissue and adjacent normal tissue. (B) AFAP1-AS1 expression levels in $66 \mathrm{GC}$ tissue was determined by reverse transcription-quantified polymerase chain reaction. The relative AFAP1-AS1 level was normalized to GAPDH. "P<0.05. ANT, adjacent normal tissue; AFAP1-AS1, AFAP1-antisense RNA 1; GC, gastric cancer; n, number.

Statistical analysis. All experiments were repeated $\geq 3$ times. Statistical analyses were performed using SPSS version 17.0 software (SPSS, Inc., Chicago, IL, USA) and GraphPad Prism 6 (GraphPad Software Inc., La Jolla, CA, USA). Differences between groups were analyzed using the $\chi^{2}$ test, Fisher's exact test, the Student's t-test or one-way analysis of variance (Kruskal-Wallis methods for the unequal variances). Multivariate survival analysis was performed using the multivariate Cox regression test. $\mathrm{P}<0.05$ was considered to indicate a statistically significant difference.

\section{Results}

Expression level of AFAP1-AS1 and clinicopathological characteristics in GC tissues. RT-qPCR was performed in order to detect AFAP1-AS1 expression level in 10 pairs of GC tissues and adjacent normal tissues. The results of RT-qPCR demonstrated that the expression level of AFAP1-AS1 was markedly upregulated in GC tissues in comparison with adjacent normal tissues (Fig. 1A; P<0.05). This indicated that AFAP1-AS1 may act as a tumor promoter in GC progression. To further investigate the association between AFAP1-AS1 expression level and clinicopathological parameters an additional 56 GC tissues were collected. Therefore, the analysis was performed using 66 cases of GC tissues. The higher expression level group $(n=33)$ and lower expression level group $(n=33)$ were categorized according to the median value of AFAP1-AS1 expression level (Fig. 1B). To identify the clinical significance of AFAP1-AS1 in $\mathrm{GC}$, clinicopathological characteristics of patients including age, sex distribution, family history, ulceration, tumor size, clinical stages and differentiation were evaluated. The results demonstrated that a higher expression level of AFAP1-AS1 was significantly associated with tumor size ( $<2$ vs. $\geq 2 \mathrm{~cm}$; $\mathrm{P}=0.046$ ), clinical stage (I-II stage vs. III-IV stage; $\mathrm{P}=0.001$ ) 
Table II. Association between AFAP1-AS1 expression level and clinicopathological characteristics of patients.

\begin{tabular}{|c|c|c|c|c|c|}
\hline \multirow[b]{2}{*}{ Factors } & \multirow[b]{2}{*}{ Number } & \multicolumn{2}{|c|}{$\begin{array}{l}\text { AFAP1-AS1 } \\
\text { expression }\end{array}$} & \multirow[b]{2}{*}{$\chi^{2}$} & \multirow[b]{2}{*}{ P-value } \\
\hline & & $\begin{array}{l}\text { High } \\
(\mathrm{n}=33)\end{array}$ & $\begin{array}{c}\text { Low } \\
(\mathrm{n}=33)\end{array}$ & & \\
\hline Age, years & & & & 0.092 & 0.319 \\
\hline$<60$ & 28 & 12 & 16 & & \\
\hline$\geq 60$ & 38 & 21 & 17 & & \\
\hline Sex distribution & & & & 1.746 & 0.186 \\
\hline Female & 21 & 8 & 13 & & \\
\hline Male & 45 & 25 & 20 & & \\
\hline Family history & & & & 1.610 & 0.205 \\
\hline Positive & 25 & 15 & 10 & & \\
\hline Negative & 41 & 18 & 23 & & \\
\hline Ulceration & & & & 0.262 & 0.609 \\
\hline Positive & 24 & 12 & 11 & & \\
\hline Negative & 42 & 20 & 22 & & \\
\hline Tumor size, cm & & & & 3.970 & 0.046 \\
\hline$<2$ & 38 & 15 & 23 & & \\
\hline$\geq 2$ & 28 & 18 & 10 & & \\
\hline Clinical stage & & & & 10.882 & 0.001 \\
\hline I-II & 41 & 14 & 27 & & \\
\hline III-IV & 25 & 19 & 6 & & \\
\hline Differentiation & & & & 11.643 & 0.003 \\
\hline Well & 22 & 5 & 17 & & \\
\hline Moderate & 27 & 15 & 12 & & \\
\hline Poor & 17 & 13 & 4 & & \\
\hline
\end{tabular}

AFAP1-AS1, AFAP1-antisense RNA 1; n, number.

and tumor differentiation $(\mathrm{P}=0.003)$, whereas no significant association was identified with the other parameters including, age, sex distribution, family history and ulceration (Table II). These results suggested that AFAP1-AS1 may serve a vital role in the development of GC.

AFAP1-AS1 expression level in predicting prognosis of patients with GC. As AFAP1-AS1 expression was significantly associated with GC progression, the present study hypothesized that a high expression level of AFAP1-AS1 may affect the prognosis of patients with GC. To further investigate the prognostic significance of AFAP1-AS1 expression, univariate and multivariate analyses were performed to identify the risk factors. Multivariate analysis revealed that AFAP1-AS1 expression (RR 95\% CI, 1.551-97.474; $\mathrm{P}=0.018$ ), clinical stage (RR 95\% CI, 1.124-12.283; $\mathrm{P}=0.031$ ) and tumor differentiation (RR 95\% CI, 0.142-0.964; $\mathrm{P}=0.042$ ) were independently associated with overall survival, whereas age, sex distribution, family history and ulceration were not (Table III).

Downregulation of AFAP1-AS1 inhibits GC cell proliferation ability. In order to further investigate the role of AFAP1-AS1
Table III. Multivariate analyses for overall survival by Cox regression test.

\begin{tabular}{|c|c|c|c|c|c|}
\hline \multirow[b]{2}{*}{ Factors } & \multirow[b]{2}{*}{ Wald } & \multirow[b]{2}{*}{ P-value } & \multirow[b]{2}{*}{$\mathrm{RR}$} & \multicolumn{2}{|c|}{ RR 95\% CI } \\
\hline & & & & Lower & Upper \\
\hline Age & 0.057 & 0.812 & 1.134 & 0.403 & 3.189 \\
\hline Sex distribution & 0.177 & 0.674 & 1.262 & 0.427 & 3.731 \\
\hline Family history & 0.268 & 0.605 & 1.323 & 0.459 & 3.816 \\
\hline Ulceration & 3.236 & 0.072 & 0.325 & 0.095 & 1.106 \\
\hline Tumor size & 0.606 & 0.436 & 0.652 & 0.222 & 1.913 \\
\hline Clinical stage & 4.627 & $0.031^{\mathrm{a}}$ & 3.715 & 1.124 & 12.283 \\
\hline Differentiation & 4.144 & $0.042^{\mathrm{a}}$ & 0.370 & 0.142 & 0.964 \\
\hline AFAP1-AS1 expression & 5.644 & $0.018^{\mathrm{a}}$ & 12.297 & 1.551 & 97.474 \\
\hline
\end{tabular}

${ }^{a} \mathrm{P}<0.05$ was considered to indicate a statistically significant difference. Wald represents the $\chi^{2}$ value. A higher Wald value indicates a greater difference between the two groups. AFAP1-AS1, AFAP1-antisense RNA 1; CI, confidence interval.

in GC, GES-1 human gastric epithelial cell line and MGC-803, BGC-823 and SGC-7901 gastric cancer cell lines were used. Firstly, RT-qPCR was performed to detect the AFAP1-AS1 expression level in gastric epithelial cell and GC cell lines. The results revealed that AFAP1-AS1 was expressed at higher levels in the GC cell lines compared with in GES-1 cells, and SGC-7901 and BGC-823 cells exhibited higher expression levels (Fig. 2A). Based on the preliminary data, the present study selected SGC-7901 and BGC-823 cells for further investigation in vitro. sh1AFAP1-AS1, sh2AFAP1-AS1 or shNC vectors were transfected into SGC-7901 and BGC-823 cells. RT-qPCR results demonstrated that the first shRNA sequence had the greatest inhibitory effect. Therefore, the sh1AFAP1-AS1 vector was selected for further study (Fig. 2B). In order to elucidate whether AFAP1-AS1 affected GC cell proliferation, CCK- 8 colorimetry was performed to determine cell viability. The results of the CCK- 8 assay revealed that proliferation rates in the sh1AFAP1-AS1 transfected group were significantly lower compared with the control group (shNC) in SGC-7901 and BGC-823 cells at 48 and $74 \mathrm{~h}$ (Fig. 2C). This indicated that downregulation AFAP1-AS1 expression markedly inhibited GC cell viability.

Downregulation of AFAPI-AS1 inhibits GC cell migration and invasion ability. Migration and invasion abilities were used to evaluate the tumor biological features. A scratch assay was performed to detect the migration of GC cells. The results revealed that SGC-7901 and BGC-823 cells in the shAFAP1-AS1 group did not exhibit the same level of space closure as shNC groups at $48 \mathrm{~h}$ (Fig. 3A), indicating that the movement ability of GC cells was significantly suppressed by knockdown of AFAP1-AS1. In addition, a Matrigel assay was performed to determine the invasion ability of GC cells. As expected, AFAP1-AS1 depletion resulted in a reduction of the number of invading cells in BGC-823 and SGC-7901 cell lines (Fig. 3B). In brief, knockdown of AFAP1-AS1 negatively regulated GC cell proliferation, 
A

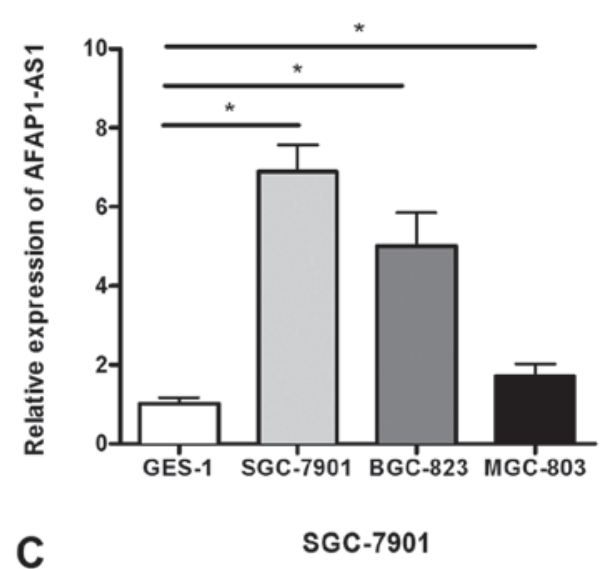

C

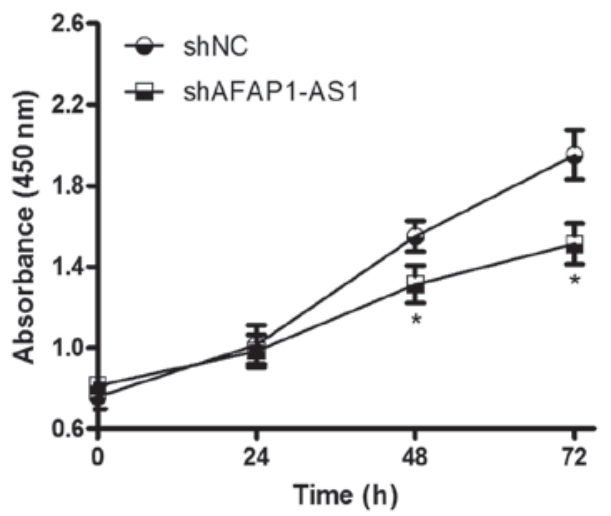

B
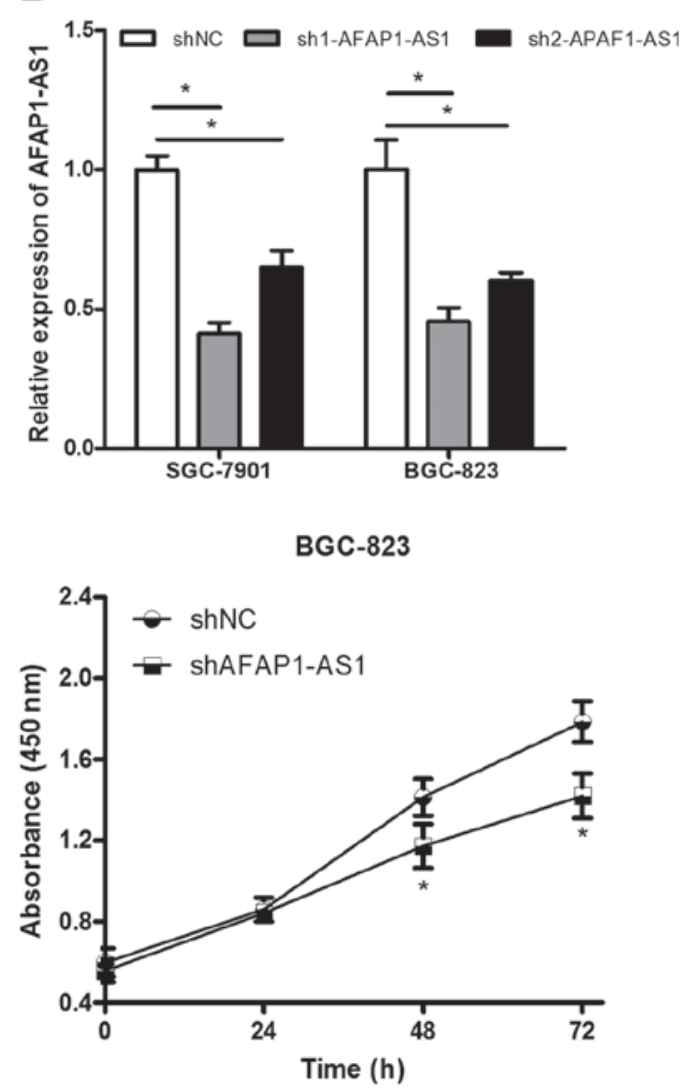

Figure 2. Downregulation of AFAP1-AS1 inhibits GC cell proliferation ability. (A) RT-qPCR was performed to analyze the expression level of AFAP1-AS1 in SGC-7901, BGC-823 and MGC-803 GC cell lines and GES-1 human gastric epithelial cell line. (B) sh1AFAP1-AS1 and sh2AFAP1-AS1, shRNA expression vectors targeting AFAP1-AS1, and a negative control shRNA vector were transfected into SGC-7901 and BGC-823 cells, respectively. RT-qPCR results revealed that the sh1AFAP1-AS1 sequence had the greatest inhibitory effect. (C) Cell Counting Kit-8 assays were performed to examine SGC-7901 and BGC-823 cell proliferation rates at the indicated time points. The results were analyzed using one-way analysis of variance and Student's t-test, "P<0.05. RT-qPCR, reverse transcription-quantitative polymerase chain reaction; AFAP1-AS1, AFAP1-antisense RNA 1; GC, gastric cancer; sh, short hairpin; shNC, scrambled control shRNA.

migration and invasion, indicating that AFAP1-AS1 may function as a tumor promoter in GC tumorigenesis.

Downregulation of AFAP1-AS1 suppresses tumor growth in nude mice. Nude mice experiments were performed to confirm the effect of the knockdown of AFAP1-AS1 in GC cells in vivo. SGC-7901 and BGC-823 cells were transfected with the shAFAP1-AS1 vector or blank empty (shNC) vector, respectively. The growth curves for each group are presented in Fig. 4A. A rapid increase in tumor volumes at day 35 in the shNC group were observed, which revealed that AFAP1-AS1 knockdown cells demonstrated significantly lower tumorigenicity $(\mathrm{P}=0.031$ for $\mathrm{SGC}-7901$ cells; $\mathrm{P}=0.008$ for BGC-823 cells). At the end of the experiment, mice were sacrificed. The mean tumor volumes of mice transfected with SGC-7901 and BGC-823 cells in the blank control

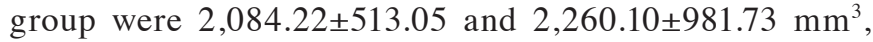
which were higher compared with the shAFAP1-AS1 group $\left(684.27 \pm 95.22\right.$ and $496.37 \pm 284.46 \mathrm{~mm}^{3}$ ), respectively (Fig. 4B and $\mathrm{C} ; \mathrm{P}<0.05)$. The tumor weight was evaluated in order to confirm the effect of AFAP1-AS1. The mean tumor weight of mice transfected with SGC-7901 and BGC-823 cells in the shNC group were $1.20 \pm 0.22$ and $1.31 \pm 0.45 \mathrm{~g}$, which was also higher compared with in the shAFAP1-AS1 group $(0.59 \pm 0.06$ and $0.42 \pm 0.22 \mathrm{~g}$; Fig. 4D; $\mathrm{P}<0.05)$. Slower tumor growth was observed in the shAFAP1-AS1 group compared with the control group.

\section{Discussion}

An increasing number of studies have suggested that understanding the function of IncRNA may provide us with a better understanding of the tumor process (16-18). For the lncRNA study of gastric cancer, the gene H19 was first reported in 2012 (12). H19 overexpression increased cellular proliferation, whereas downregulation of H19 increased the rate of apoptosis, which was associated with p53 inactivation (19). Previous studies have confirmed that the dysregulation of lncRNAs participates in GC development $(20,21)$. Liu et al (22) demonstrated that the upregulation HOX transcription antisense RNA (HOTAIR) was associated with tumor size and metastasis and represented a biomarker of poor prognosis in gastric cancer. HOTAIR depletion significantly suppressed cell viability and invasion in vitro and in vivo. Antisense RNA in the INK4 locus (23) and colon cancer-associated transcription 1 (24) have been characterized to have a growth-promotion function, whereas FOXF1 adjacent non-coding developmental regulatory RNA (25), 
A

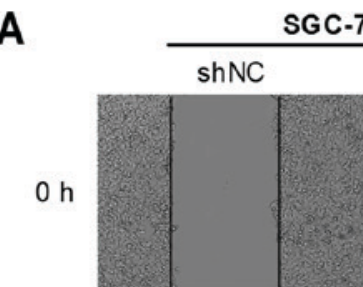

SGC-79017
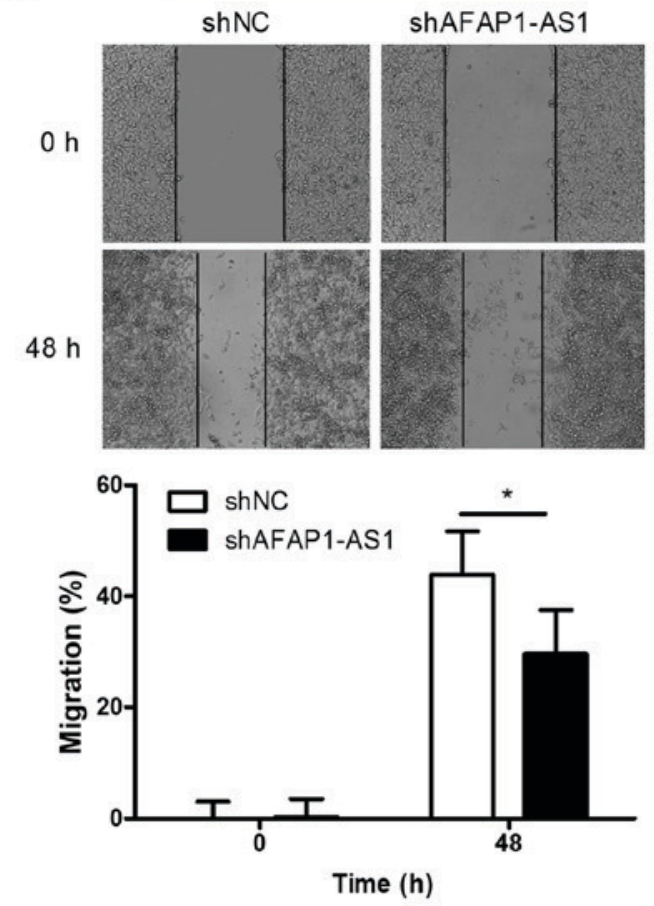

B

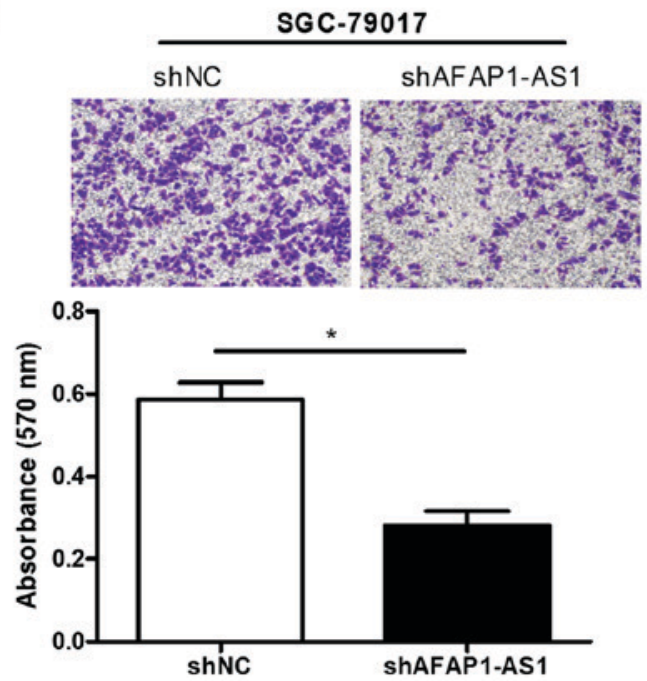

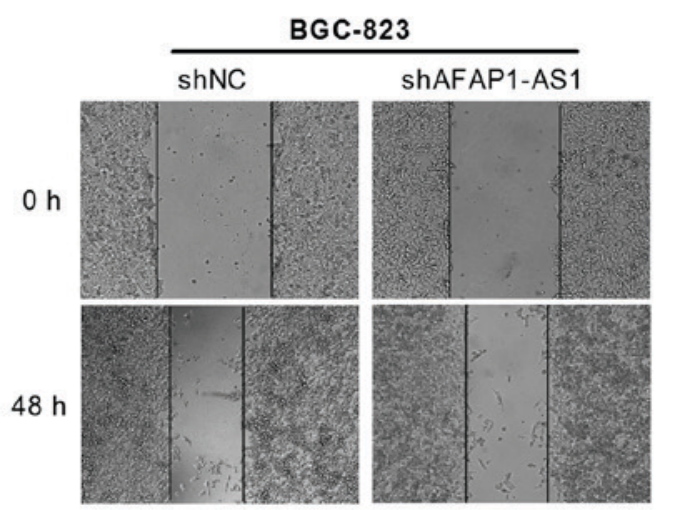
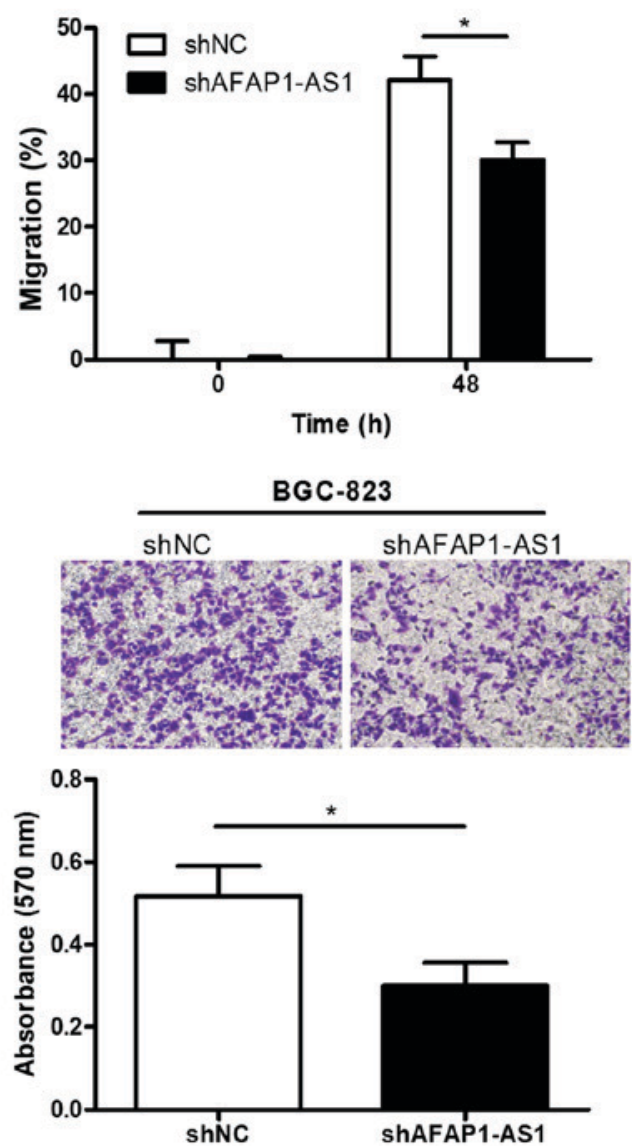

Figure 3. Downregulation of AFAP1-AS1 inhibits GC cell migration and invasion ability. SGC-7901 and BGC-823 cells were used to detect the ability of migration and invasion. (A) Migration of cells into the scratched area was monitored at the indicated time points. Representative microscopic images (magnification, $\mathrm{x} 40$ ) and the migration rates of each groups at 0 and $48 \mathrm{~h}$ are presented. (B) Representative microscopic images of invasive cells from the shNC and shAPAF1-AS1 groups (top panel; magnification, x100). The relative number of invaded cells in each group was measured by determining the absorbance at $570 \mathrm{~nm}$ (bottom panel). Data were assessed by Student's t-test. "P<0.05. AFAP1-AS1, AFAP1-antisense RNA 1; GC, gastric cancer; sh, short hairpin; shNC, scrambled control shRNA.

double homeobox A pseudogene 8 (26), metastasis associated lung adenocarcinoma transcript 1 (27) and HOXA distal transcript antisense RNA (28) have been confirmed to have metastatic-promotion functions in GC.

AFAP1-AS1, also known as LOC84740, is located on chromosome Chr4p16.1 and acts as an antisense lncRNA, which functions as a regulator of the AFAPl gene (29). AFAP1-AS1 expression is frequently upregulated and serves a vital role in a variety of tumor types, including colorectal cancer, hepatocellular carcinoma, esophageal squamous cancer and non-small cell lung cancer (30-34). A previous study identified 186 upregulated and 294 downregulated
lncRNAs that were expressed with significantly differential expression levels in GC via lncRNA microarray-analysis, including AFAP1-AS1 (14). However, the detail mechanisms of AFAP1-AS1 underlying GC progression require further investigation. The present study first detected the AFAP1-AS1 expression level in 10 pairs of GC and adjacent tissues by RT-qPCR, and a higher expression level in GC tissues compared with in adjacent tissues was revealed. This result was consistent with a previous study (7). In order to determine whether AFAP1-AS1 acts as a tumor promoter in GC, the number of GC tissue samples analyzed was increased and the association between AFAP1-AS1 expression level 
A

SGC-7901

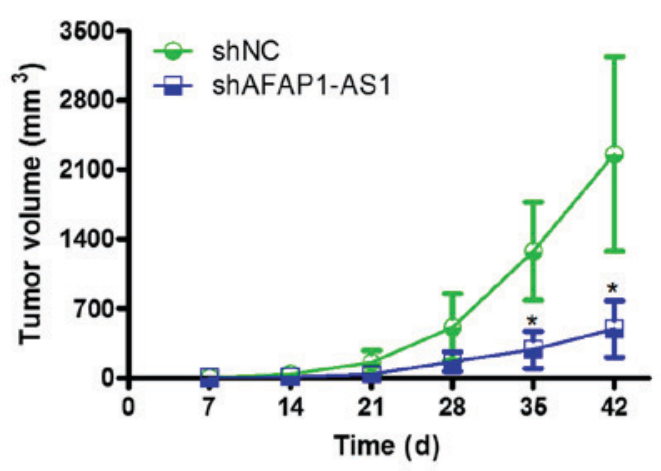

B

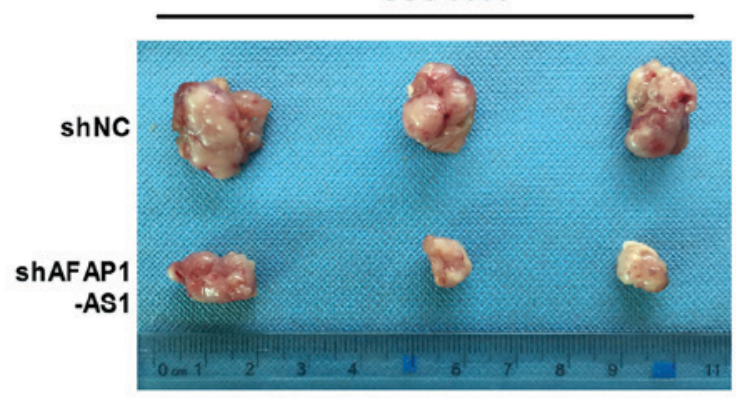

C

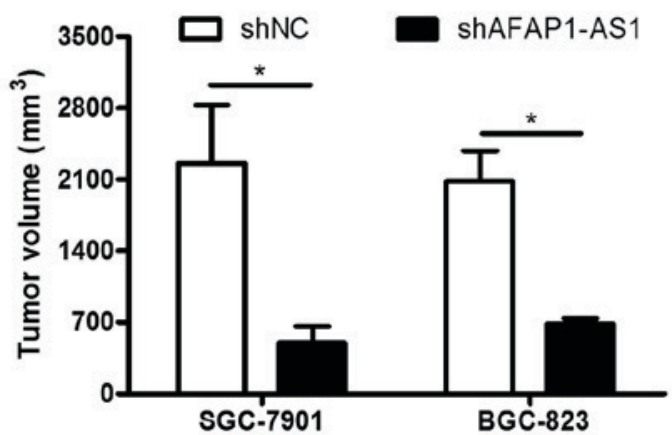

BGC-823

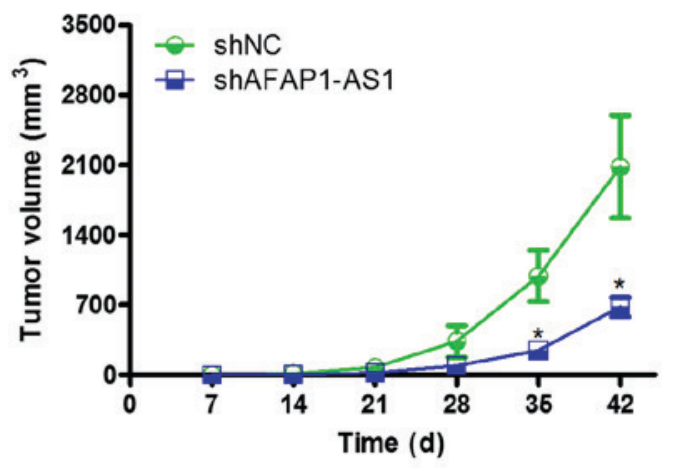

BGC-823

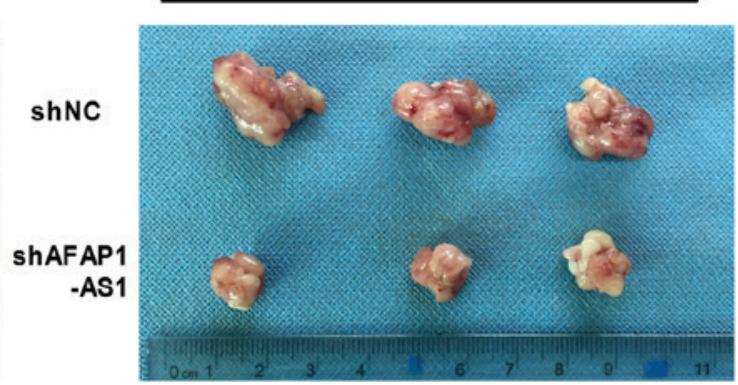

D

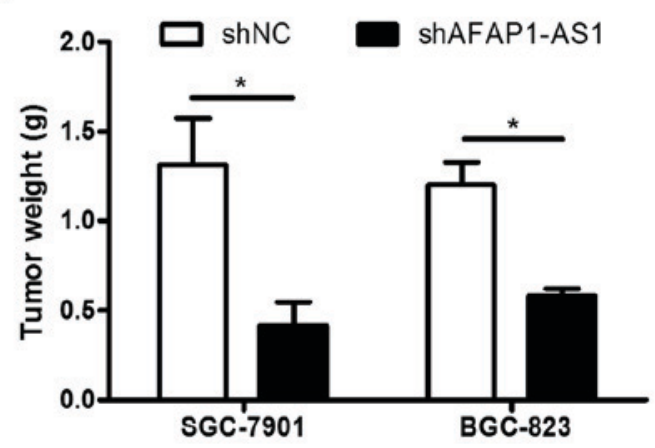

Figure 4. Downregulation of AFAP1-AS1 suppresses tumor growth in vivo. (A) Growth curve of nude mice demonstrating various levels of AFAP1-AS1 expression. (B) Representative images of subcutaneous tumors at day 42. (C) Tumor volume and (D) mass of SGC-7901 and BGC-823 cell xenografts in the negative control and knockdown AFAP1-AS1 groups. The results were analyzed using Student's t-test. "P<0.05. AFAP1-AS1, AFAP1-antisense RNA 1; sh, short hairpin; shNC, scrambled control shRNA.

and clinicopathological parameters was investigated. The results indicated that AFAP1-AS1 expression level was positively correlated with GC development. A high AFAP1-AS1 expression level was associated with poor prognosis in GC patients by performing multivariate Cox regression test analysis. In order to explore the effect of AFAP1-AS1 in vitro, the expression AFAP1-AS1 was downregulated in SGC-7901 and BGC-823 cells. The CCK-8 assays revealed that a low expression level of AFAP1-AS1 suppressed the proliferation of GC cells. Scratch and Matrigel assays demonstrated that downregulation AFAP1-AS1 inhibits cell migration and invasion abilities. To further explore the promotional role of AFAP1-AS1, experiments using mice were performed. The transfected SGC-7901 or BGC-823 cells were injected in nude mice subcutaneously. A total of 42 days following implantation, mice were sacrificed and the xenograft tumor was dissected. The mean volume and weight of tumors in the shNC group was greater compared with that in the sh1AFAP1-AS1 group. Taken together, these findings suggested that reducing AFAP1-AS1 expression level significantly inhibited GC development. However, the exact mechanisms underlying AFAP1-AS1 remain to be elucidated. In future studies, a greater number of GC tissue samples should be obtained in order to reach a more credible conclusion regarding the role of AFAP1-AS1. The target genes of AFAP1-AS1 and relevant downstream signaling pathways also require further investigation.

In conclusion, the present study demonstrated that AFAP1-AS1 expression level was markedly upregulated in GC tissues and cell lines. Downregulation of AFAP1-AS1 inhibited cell proliferation, invasion and migration in vitro and also tumor growth of GC cells in vivo. These results indicated that AFAP1-AS1 may serve as a novel prognostic marker and tumor promoter in GC, and the newly identified AFAP1-AS1 may provide a promising molecular target for anticancer therapy. 


\section{Acknowledgements}

The present study was supported by the Hunan Institute of Technology (grant nos. 2016JC2048 and 20162050).

\section{References}

1. Min J, Choi B, Han TS, Lee HJ, Kong SH, Suh YS, Kim TH, Choe HN, Kim WH, Hur K and Yang HK: Methylation levels of LINE-1 as a useful marker for venous invasion in both FFPE and frozen tumor tissues of gastric cancer. Mol Cells 40: 346-354, 2017.

2. Jemal A, Bray F, Center MM, Ferlay J, Ward E and Forman D: Global cancer statistics. CA Cancer J Clin 61: 69-90, 2011.

3. Siegel R, Ma J, Zou Z and Jemal A: Cancer statistics, 2014. CA Cancer J Clin 64: 9-29, 2014

4. Lichthardt S, Kerscher A, Dietz UA, Jurowich C, Kunzmann V, von Rahden BH, Germer CT and Wiegering A: Original article: Role of adjuvant chemotherapy in a perioperative chemotherapy regimen for gastric cancer. BMC Cancer 16: 650, 2016.

5. Caruso S, Patriti A, Roviello F, De Franco L, Franceschini F, Coratti A and Ceccarelli G: Laparoscopic and robot-assisted gastrectomy for gastric cancer: Current considerations. World J Gastroenterol 22: 5694-5717, 2016

6. Shi J, Gao P, Song Y, Chen X, Li Y, Zhang C, Wang H and Wang Z: Efficacy and safety of taxane-based systemic chemotherapy of advanced gastric cancer: A systematic review and meta-analysis. Sci Rep 7: 5319, 2017.

7. Chan WL, Yuen KK, Siu SW, Lam KO and Kwong DL: Third-line systemic treatment versus best supportive care for advanced/metastatic gastric cancer: A systematic review and meta-analysis. Crit Rev Oncol Hematol 116: 68-81, 2017.

8. Wu Y, Cain-Hom C, Choy L, Hagenbeek TJ, de Leon GP, Chen Y, Finkle D, Venook R, Wu X, Ridgway J, et al: Therapeutic antibody targeting of individual Notch receptors. Nature 464 $1052-1057,2010$

9. Zhang L, Zhou Y, Huang T, Cheng AS, Yu J, Kang W and To KF: The interplay of LncRNA-H19 and its binding partners in physiological process and gastric carcinogenesis. Int J Mol Sci 18: pii: E450, 2017.

10. Sas-Chen A, Srivastava S and Yarden Y: The short and the long: Non-coding RNAs and growth factors in cancer progression. Biochem Soc Trans 45: 51-64, 2017.

11. Bhan A, Soleimani M and Mandal SS: Long noncoding RNA and cancer: A new paradigm. Cancer Res 77: 3965-3981, 2017.

12. Zhang $\mathrm{M}$ and $\mathrm{Du} \mathrm{X}$ : Noncoding RNAs in gastric cancer: Research progress and prospects. World J Gastroenterol 22 6610-6618, 2016

13. Wang J, Sun J, Wang J, Song Y, Gao P, Shi J, Chen P and Wang Z: Long noncoding RNAs in gastric cancer: functions and clinical applications. Onco Targets Ther 9: 681-697, 2016

14. Guo X, Yang Z, Zhi Q, Wang D, Guo L, Li G, Miao R, Shi Y and Kuang Y: Long noncoding RNA OR3A4 promotes metastasis and tumorigenicity in gastric cancer. Oncotarget 7: 30276-30294, 2016.

15. Qiu JJ, Lin YY, Ding JX, Feng WW, Jin HY and Hua KQ: Long non-coding RNA ANRIL predicts poor prognosis and promotes invasion/metastasis in serous ovarian cancer. Int J Oncol 46 : 2497-2505, 2015

16. Livak KJ and Schmittgen TD: Analysis of relative gene expression data using real-time quantitative PCR and the 2(-Delta Delta C(T)) method. Methods 25: 402-408, 2001.

17. Zhou CC, Yang F, Yuan SX, Ma JZ, Liu F, Yuan JH, Bi FR, Lin KY, Yin JH, Cao GW, et al: Systemic genome screening identifies the outcome associated focal loss of long noncoding RNA PRAL in hepatocellular carcinoma. Hepatology 63: $850-863,2016$

18. Nie W, Ge HJ, Yang XQ, Sun X, Huang H, Tao X, Chen WS and Li B: LncRNA-UCA1 exerts oncogenic functions in non-small cell lung cancer by targeting miR-193a-3p. Cancer Lett 371: 99-106, 2016
19. Zhang JY, Weng MZ, Song FB, Xu YG, Liu Q, Wu JY, Qin J, Jin T and Xu JM: Long noncoding RNA AFAP1-AS1 indicates a poor prognosis of hepatocellular carcinoma and promotes cell proliferation and invasion via upregulation of the RhoA/Rac2 signaling. Int J Oncol 48: 1590-1598, 2016.

20. Yang F, Bi J, Xue X, Zheng L, Zhi K, Hua J and Fang G: Up-regulated long non-coding RNA H19 contributes to proliferation of gastric cancer cells. FEBS J 279: 3159-3165, 2012.

21. Sun W, Yang Y, Xu C, Xie Y and Guo J: Roles of long noncoding RNAs in gastric cancer and their clinical applications. J Cancer Res Clin Oncol 142: 2231-2237, 2016.

22. Liu XH, Sun M, Nie FQ, Ge YB, Zhang EB, Yin DD, Kong R, Xia R, Lu KH, Li JH, De W, Wang KM and Wang ZX: Lnc RNA HOTAIR functions as a competing endogenous RNA to regulate HER 2 expression by sponging miR-331-3p in gastric cancer. Mol Cancer 13: 92, 2014.

23. Wang J, Sun J, Wang J, Song Y, Gao P, Shi J, Chen P and Wang Z: Long noncoding RNAs in gastric cancer: Functions and clinical applications. Onco Targets Ther 9: 681-697, 2016.

24. Lan WG, Xu DH, Xu C, Ding CL, Ning FL, Zhou YL, Ma LB, Liu CM and Han X: Silencing of long non-coding RNA ANRIL inhibits the development of multidrug resistance in gastric cancer cells. Oncol Rep 36: 263-270, 2016.

25. He X, Tan X, Wang X, Jin H, Liu L, Ma L, Yu H and Fan Z: C-Myc-activated long noncoding RNA CCAT1 promotes colon cancer cell proliferation and invasion. Tumour Biol 35: 12181-12188, 2014.

26. Xu TP, Huang MD, Xia R, Liu XX, Sun M, Yin L, Chen WM, Han L, Zhang EB, Kong R, et al: Decreased expression of the long non-coding RNA FENDRR is associated with poor prognosis in gastric cancer and FENDRR regulates gastric cancer cell metastasis by affecting fibronectin1 expression. J Hematol Oncol 7: 63, 2014.

27. Ma HW, Xie M, Sun M, Chen TY, Jin RR, Ma TS, Chen QN, Zhang EB, He XZ, De W and Zhang ZH: The pseudogene derived long noncoding RNA DUXAP8 promotes gastric cancer cell proliferation and migration via epigenetically silencing PLEKHO1 expression. Oncotarget 8: 52211-52224, 2016.

28. Deng QJ, Xie LQ and Li H: Overexpressed MALAT1 promotes invasion and metastasis of gastric cancer cells via increasing EGFL7 expression. Life Sci 157: 38-44, 2016.

29. Ye H, Liu K and Qian K: Overexpression of long noncoding RNA HOTTIP promotes tumor invasion and predicts poor prognosis in gastric cancer. Onco Targets Ther 9: 2081-2088, 2016.

30. Bo H, Gong Z, Zhang W, Li X, Zeng Y, Liao Q, Chen P, Shi L, Lian Y, Jing Y, et al: Upregulated long non-coding RNA AFAP1-AS1 expression is associated with progression and poor prognosis of nasopharyngeal carcinoma. Oncotarget 6 : 20404-20418, 2015.

31. Wang F, Ni H, Sun F, Li M and Chen L: Overexpression of lncRNA AFAP1-AS1 correlates with poor prognosis and promotes tumorigenesis in colorectal cancer. Biomed Pharmacother 81: 152-159, 2016.

32. Yang F, Lyu S, Dong S, Liu Y, Zhang X and Wang O: Expression profile analysis of long noncoding RNA in HER-2-enriched subtype breast cancer by next-generation sequencing and bioinformatics. Onco Targets Ther 9: 761-772, 2016.

33. Zhou XL, Wang WW, Zhu WG, Yu CH, Tao GZ, Wu QQ, Song YQ,Pan P and Tong YS: High expression of long non-coding RNA AFAP1-AS1 predicts chemoradioresistance and poor prognosis in patients with esophageal squamous cell carcinoma treated with definitive chemoradiotherapy. Mol Carcinog 55: 2095-2105, 2016

34. Deng J, Liang Y, Liu C, He S and Wang S: The up-regulation of long non-coding RNA AFAP1-AS1 is associated with the poor prognosis of NSCLC patients. Biomed Pharmacother 75: 8-11, 2015 .

This work is licensed under a Creative Commons Attribution-NonCommercial-NoDerivatives 4.0 International (CC BY-NC-ND 4.0) License. 